\title{
SUBSTITUIÇÃO DE SILAGEM DE MILHO POR CANA-DE-AÇÚCAR E CAROÇO DE ALGODÃO SOBRE O DESEMPENHO DE VACAS HOLANDESAS EM LACTAÇÃO
}

\author{
Alexandre Vaz Pires, ${ }^{1 *}$ Ivanete Susin, ${ }^{1}$ José Manuel Corrêa de Simas,${ }^{2}$ Reinaldo Cunha de Oliveira \\ Júnior, ${ }^{3}$ Juliano José de Resende Fernandes, ${ }^{4}$ Rafael Canonenco de Araujo ${ }^{1}$ e Clayton Quirino Mendes ${ }^{5}$ \\ 1. Departamento de Zootecnia, Escola Superior de Agricultura Luiz de Queiroz, Universidade de São Paulo, Piracicaba, SP \\ 2. PhD, Elanco Saúde Animal \\ 3. Universidade Estadual de Goiás, Faculdade de Zootecnia, São Luiz dos Montes Belos, GO \\ 4. Escola de Veterinária, Universidade Federal de Goiás, Goiânia, GO \\ 5. Doutor em Ciência Animal e Pastagem da ESALQ/USP. \\ *Autor correspondente: E-mail: alvpires@esalq.usp.br
}

RESUMO

Cinco vacas holandesas multíparas (média de $526 \mathrm{~kg}$ de peso vivo e 85 dias de lactação) foram distribuídas em delineamento quadrado latino $5 \times 5$ para avaliar a substituição de silagem de milho por cana-de-açúcar mais caroço de algodão em rações contendo $50 \%$ de concentrado e $50 \%$ de volumoso (base matéria seca - MS). Os tratamentos consistiram na substituição de silagem de milho por cana-de-açúcar picada, nas seguintes proporções: 100:0 (controle), 75:25, 50:50, 25:75 e 0:100, com base na MS do volumoso. A cada tratamento, adicionaram-se $0 \%, 5 \%, 10 \%, 15 \%$ e $20 \%$ de caroço de algodão na MS da dieta, respectivamente. Os consumos de MS das vacas recebendo as rações com 100\%,75\% e
$50 \%$ de silagem de milho foram maiores $(P<0,05)$ do que os das vacas recebendo $25 \%$ e $0 \%$ de silagem de milho. A produção de leite foi maior $(P<0,05)$ para as vacas recebendo $100 \%, 75 \%$ ou $50 \%$ de silagem de milho do que para as vacas recebendo $25 \%$ ou $0 \%$ de silagem de milho. $\mathrm{O}$ teor de gordura mostrou-se maior $(P<0,05)$ para vacas recebendo $50 \%, 25 \%$ ou $0 \%$ de silagem de milho do que para as vacas que receberam os demais tratamentos. $\mathrm{O}$ teor de proteína não foi afetado $(P>0,05)$ pela inclusão de cana-de-açúcar à dieta. A silagem de milho pode ser substituída por cana-de-açúcar até $50 \%$ do volumoso sem efeitos negativos no desempenho de vacas em lactação produzindo até $18 \mathrm{~L} /$ dia de leite.

PALAVRAS-CHAVES: Caroço de algodão, composição do leite, consumo de matéria seca, produção de leite.

\section{ABSTRACT}

\section{REPLACEMENT OF CORN SILAGE BY CHOPPED SUGAR CANE AND WHOLE COTTONSEED ON THE PERFORMANCE OF LACTATING HOLSTEIN COWS}

Five multiparous Holstein cows averaging $526 \mathrm{~kg}$ of body weight and 85 days of lactation were assigned in a $5 \times 5$ latin square design for the evaluation of the replacement of corn silage by sugar cane and whole cottonseed. Cows were fed a 50:50 concentrate:forage diet (dry matter basis-DM). Treatments were defined by the replacement of corn silage by chopped sugar cane (whole plant) according to the following proportions: 100:0 (control), 75:25, 50:50, 25:75, 0:100, based on dry matter roughage. In each treatment, $0,5,10,15$, and $20 \%$ of whole cottonseed were added to the dietary DM, respectively. Dry matter intake (DMI) of cows fed 100, 75, and 50\% corn silage diets was higher $(P<0.05)$ than the DMI of cows fed 25 and $0 \%$ corn silage. Milk production was higher $(P<0.05)$ for cows fed 100, 75 and 50\% corn silage than for cows fed 25 or $0 \%$ corn silage. Milk fat concentration was higher $(P<0.05)$ for cows fed 50, 25 or $0 \%$ corn silage than for cows fed 100 or $75 \%$ corn silage. Milk protein concentration was not affected $(P>0.05)$ by inclusion of sugar cane and whole cottonseed. Corn silage can be replaced by sugar cane up to $50 \%$ of roughage level without negative effect on performance of dairy cows producing up to $18 \mathrm{~kg}$ milk/day.

KEYWORDS: Cottonseed, dry matter intake, milk composition, milk production. 


\section{INTRODUÇÃO}

Dado o grande potencial de produção de matéria seca (MS) e energia por unidade de área, a cana-de-açúcar é amplamente utilizada na alimentação de bovinos leiteiros confinados. A utilização dessa forrageira permite obter custo de produção relativamente mais baixo do que o observado com o uso de alimentos volumosos normalmente utilizados no período da seca como, por exemplo, as silagens de milho e sorgo.

Uma das grandes limitações da utilização da cana-de-açúcar refere-se ao baixo consumo de matéria seca (CMS) dos animais quando comparada com o CMS de outras fontes de volumosos (MENDONÇA et al., 2004; MAGALHÃES et al., 2006). Essa redução no CMS é normalmente atribuída à baixa digestibilidade da fração fibrosa e/ ou às baixas taxas de digestão e passagem da fibra da cana-de-açúcar no rúmen.

Vários autores constataram que a cana-deaçúcar quando usada em substituição à silagem de milho provocou redução na produção de leite, assim como na produção de leite corrigida para gordura (VALVASORI et al., 1995; MAGALHÃES et al., 2004; COSTA et al., 2005). Segundo esses autores, o menor desempenho das vacas alimentadas com cana-de-açúcar como principal volumoso é justificado, principalmente, pelo menor CMS.

Dessa forma, sugere-se que o uso de caroço de algodão, por ser alimento rico em gordura e possuir elevada concentração energética (NRC, 2001), pode compensar o menor CMS verificado quando se inclui cana-de-açúcar, mantendo-se o consumo de energia e o desempenho de vacas em lactação dentro de padrões adequados.

O objetivo deste trabalho foi determinar os efeitos da substituição de silagem de milho por cana-de-açúcar mais caroço de algodão sobre a produção e a composição do leite de vacas holandesas em lactação.

\section{MATERIAL E MÉTODOS}

Cinco vacas holandesas multíparas fistuladas no rúmen (média de $526 \mathrm{~kg}$ de peso vivo - PV e 85 dias de lactação) foram utilizadas em delinea- mento quadrado latino $5 \times 5$. Alimentaram-se as vacas com rações contendo $50 \%$ de concentrado e $50 \%$ de volumoso (base seca). Os tratamentos foram determinados pela substituição da silagem de milho por cana-de-açúcar picada (planta inteira) conforme as proporções: 100:0 (controle), 75:25, 50:50, 25:75 e 0:100, com base na MS do volumoso. A cada tratamento adicionou-se $0 \%, 5 \%, 10 \%$, $15 \%$ e $20 \%$ de caroço de algodão na MS da dieta, respectivamente.

Os efeitos deletérios da adição excessiva de fontes suplementares de gordura sobre a fermentação ruminal e a degradabilidade da fibra são amplamente conhecidos (PALMQUIST \& MATTOS, 2006). Em geral, recomenda-se o teor máximo de $7 \%$ de extrato etéreo na MS da dieta (NRC, 2001). Portanto, o nível máximo de inclusão de caroço de algodão usado neste experimento foi $20 \%$ da MS da dieta, sendo 5,4\% o teor máximo de extrato etéreo.

Procedeu-se ao balanceamento do concentrado de forma a tornar as rações isonitrogenadas (Tabela 1). Cada período experimental foi constituído de quatorze dias, sendo os primeiros dez dias para adaptação aos tratamentos e os quatro últimos utilizados para colheita de dados e de amostras.

As rações completas foram preparadas e fornecidas ad libitum duas vezes ao dia, permitindo-se sobra de 5\% do oferecido. Amostras do alimento oferecido e recusado foram colhidas diariamente durante os últimos quatro dias, sendo em seguida congeladas.

Amostras das rações experimentais e das sobras foram analisadas no Laboratório de Bromatologia do Departamento de Zootecnia da ESALQ/ USP. Depois de descongeladas, secaram-se as amostras em estufa por $72 \mathrm{~h}$ a $55^{\circ} \mathrm{C}$, sendo moídas em moinho tipo Wiley com peneiras de crivos de $1 \mathrm{~mm}$.

Amostras do alimento oferecido e recusado foram analisadas quanto aos teores de MS, matéria mineral (MM), proteína bruta (PB) e extrato etéreo (EE), segundo a AOAC (1990); fibra em detergente neutro (FDN), segundo VAN SOEST et al. (1991); fibra em detergente ácido (FDA) e lignina, de acordo com GOERING \& VAN SOEST (1970). 
TABELA 1. Proporção dos ingredientes e composição química das rações (\% da MS)

\begin{tabular}{|c|c|c|c|c|c|}
\hline \multirow{2}{*}{ Variáveis } & \multicolumn{5}{|c|}{ Tratamentos $^{1}$} \\
\hline & $100 \% \mathrm{SM}$ & $75 \%$ SM $25 \% \mathrm{C}$ & $\begin{array}{c}50 \% \text { SM } 50 \% \\
\text { C }\end{array}$ & $\begin{array}{l}25 \% \mathrm{SM} \\
75 \% \quad \mathrm{C}\end{array}$ & $100 \% \mathrm{C}$ \\
\hline \multicolumn{6}{|l|}{ Ingredientes } \\
\hline Silagem de milho & 50,0 & 37,5 & 25,0 & 12,5 & --- \\
\hline Cana-de-açúcar & --- & 12,5 & 25,0 & 37,5 & 50,0 \\
\hline Milho moído & 26,7 & 21,7 & 16,7 & 11,7 & 6,7 \\
\hline Farelo de soja & 20,0 & 20,0 & 20,0 & 20,0 & 20,0 \\
\hline Caroço de algodão & --- & 5,0 & 10,0 & 15,0 & 20,0 \\
\hline Minerais & 2,7 & 2,7 & 2,7 & 2,7 & 2,7 \\
\hline Ureia & 0,6 & 0,6 & 0,6 & 0,6 & 0,6 \\
\hline \multicolumn{6}{|l|}{ Composição química } \\
\hline Matéria seca, base úmida & 46,15 & 46,07 & 45,23 & 45,17 & 45,41 \\
\hline Matéria mineral & 6,70 & 6,10 & 6,26 & 6,42 & 6,00 \\
\hline Proteína bruta & 18,24 & 18,39 & 17,45 & 18,51 & 17,42 \\
\hline Extrato etéreo & 3,50 & 4,07 & 4,52 & 4,94 & 5,43 \\
\hline $\mathrm{FDN}^{2}$ & 27,36 & 28,29 & 30,73 & 29,88 & 33,70 \\
\hline $\mathrm{FDA}^{3}$ & 17,29 & 18,60 & 20,85 & 20,54 & 24,28 \\
\hline Lignina & 2,82 & 3,05 & 3,93 & 3,84 & 6,05 \\
\hline $\mathrm{EL}_{\mathrm{L}}, \mathrm{Mcal} / \mathrm{kg}^{4}$ & 1,79 & 1,74 & 1,69 & 1,66 & 1,62 \\
\hline
\end{tabular}

${ }^{1}$ Porcentagens baseadas na proporção dos volumosos na matéria seca das rações; $\mathrm{SM}=$ silagem de milho; $\mathrm{C}$ = cana-de-açúcar; ${ }^{2} \mathrm{FDN}=$ fibra em detergente neutro;

${ }^{3} \mathrm{FDA}=$ fibra em detergente ácido;

${ }^{4} \mathrm{EL}_{\mathrm{L}}=$ energia líquida de lactação, estimada pelo programa CNCPS Versão 5.0.40 (FOX et al., 2004).

Registrou-se a produção de leite duas vezes ao dia durante o período de colheita de cada período. Colheram-se amostras de leite proporcionais à produção de cada período (manhã e tarde) para a determinação das concentrações de proteína e gordura. O delineamento estatístico utilizado foi o quadrado latino 5 x 5 . Analisaram-se os dados por meio da GLM (SAS, 1991). Para a obtenção das médias, utilizou-se o comando LSMEANS do SAS (1991). Diferenças estatísticas foram consideradas a $5 \%$ de probabilidade pelo Teste Tukey.

\section{RESULTADOS E DISCUSSÃO}

Os CMS (Tabela 2) das vacas alimentadas com as rações constituídas por $100 \%, 75 \%$ e $50 \%$ de silagem de milho foram maiores $(P>0,05)$ do que os CMS das vacas alimentadas com $25 \%$ e $0 \%$ de silagem de milho. PRESTON (1976) e PRESTON (1978) também observaram queda no CMS quando a silagem de milho foi substituída pela cana-de-açúcar. PATE (1981) observou correlações negativas $(r=-0,93)$ entre a 
porcentagem de cana-de-açúcar na dieta e o CMS. Os dados obtidos também estão de acordo com os observados por NOGUEIRA FILHO et al. (1977), no qual a silagem de sorgo foi substituída pela cana-de-açúcar na alimentação de vacas em lactação.

TABELA 2. Efeito da substituição da silagem de milho por cana-de-açúcar mais caroço de algodão sobre o consumo de matéria seca, produção e composição de leite de vacas holandesas em lactação

\begin{tabular}{lcccccc}
\hline & \multicolumn{5}{c}{ Tratamentos $^{2}$} & \\
\cline { 2 - 5 } Variáveis $^{1}$ & $100 \% \mathrm{SM}$ & $75 \% \mathrm{SM}$ & $50 \% \mathrm{SM}$ & $25 \% \mathrm{SM}$ & $100 \% \mathrm{C}$ & \\
\hline CMS, kg/dia & $14,86^{\mathrm{a}}$ & $14,31^{\mathrm{a}}$ & $14,30^{\mathrm{a}}$ & $11,84^{\mathrm{b}}$ & $11,37^{\mathrm{b}}$ & 0,82 \\
Produção de leite, kg/dia & $16,51^{\mathrm{ab}}$ & $16,60^{\mathrm{ab}}$ & $18,08^{\mathrm{a}}$ & $14,83^{\mathrm{b}}$ & $13,33^{\mathrm{c}}$ & 1,16 \\
PLCG, kg/dia & $13,91^{\mathrm{b}}$ & $14,57^{\mathrm{ab}}$ & $16,28^{\mathrm{a}}$ & $13,14^{\mathrm{b}}$ & $12,64^{\mathrm{b}}$ & 0,82 \\
Gordura, \% & $2,98^{\mathrm{b}}$ & $3,07^{\mathrm{b}}$ & $3,34^{\mathrm{ab}}$ & $3,39^{\mathrm{ab}}$ & $3,59^{\mathrm{a}}$ & 0,21 \\
Gordura, kg/dia & $0,49^{\mathrm{b}}$ & $0,53^{\mathrm{ab}}$ & $0,60^{\mathrm{a}}$ & $0,48^{\mathrm{b}}$ & $0,49^{\mathrm{b}}$ & 0,03 \\
Proteína, \% & 2,94 & 2,98 & 3,03 & 2,92 & 3,06 & 0,12 \\
Proteína, kg/dia & $0,49^{\mathrm{a}}$ & $0,50^{\mathrm{a}}$ & $0,55^{\mathrm{a}}$ & $0,43^{\mathrm{b}}$ & $0,39^{\mathrm{b}}$ & 0,04 \\
PLCG:CMS & $0,92^{\mathrm{b}}$ & $1,03^{\mathrm{ab}}$ & $1,10^{\mathrm{ab}}$ & $1,17^{\mathrm{a}}$ & $1,13^{\mathrm{ab}}$ & 0,09 \\
\hline
\end{tabular}

${ }^{1} \mathrm{CMS}$ = consumo de matéria seca; $\mathrm{PLCG}=$ produção de leite corrigida para $4 \%$ de gordura;

${ }^{2}$ Porcentagens baseadas na proporção dos volumosos na matéria seca das rações; $\mathrm{SM}=$ silagem de milho; $\mathrm{C}=$ cana-de-açúcar; $\mathrm{a}, \mathrm{b}=$ médias seguidas de letras distintas nas linhas indicam diferenças significativas pelo Teste de Tukey $(P<0,05)$.

${ }^{3} \mathrm{EPM}=$ erro-padrão da média.

MAGALHÃES et al. (2004) verificaram que, para cada $1 \%$ de inclusão de cana-de-açúcar em substituição à silagem de milho, houve redução de 0,0266 $\mathrm{kg}$ no CMS $\left(\mathrm{r}^{2}=0,98\right)$. COSTA et al. (2005) constataram que vacas em lactação que consumiram ração contendo $60 \%$ de silagem de milho ingeriram 19,32 $\mathrm{kg}$ de MS, ao passo que vacas que consumiram ração contendo $60 \%$ de cana-de-açúcar na MS ingeriram $15,77 \mathrm{~kg}$ de MS.

Segundo PRESTON (1982), a redução do CMS causada pela cana-de-açúcar é fruto da reduzida taxa de digestão e/ou da baixa digestibilidade ruminal de sua fração fibrosa. MAGALHÃES et al. (2006) verificaram que a inclusão de cana-de-açúcar em substituição total à silagem de milho causou redução na taxa de passagem ruminal de $5,84 \%$ para $5,27 \% / \mathrm{h}$. Isso comprova a teoria de maior acúmulo de material indigestível no rúmen, o que aumenta o efeito de enchimento, causando menor CMS (ALLEN, 2000).
A produção de leite foi maior $(P<0,05)$ nas vacas alimentadas com a ração contendo $50 \%$ de silagem de milho quando comparada com as rações contendo $25 \%$ ou $0 \%$ de silagem de milho (Tabela 2 ). Concluiuse que a inclusão de caroço de algodão, como forma de aumentar a densidade energética da ração, não foi capaz de manter um mesmo padrão de desempenho para os animais recebendo rações contendo $25 \%$ ou $0 \%$ de silagem de milho. As produções dos tratamentos contendo $100 \%, 75 \%$ ou $50 \%$ de silagem de milho não diferiram entre si $(P>0,05)$.

Ao substituírem silagem de milho por cana-deaçúcar, MAGALHÃES et al. (2004) verificaram produções de leite de 24,17; 23,28; 22,10 e 20,36 kg/dia para vacas em lactação alimentadas com $0 \%, 20 \%, 40 \%$ e $60 \%$ de canade-açúcar na MS da ração, respectivamente. Os mesmos autores verificaram, pelo cálculo da equação de regressão, que para cada $1 \%$ de inclusão de cana-de-açúcar na MS da ração houve queda de $0,038 \mathrm{~kg}$ de leite/dia. 
NAUFEL et al. (1969), ao compararem a cana-de-açúcar com silagens de milho, de sorgo e de capim napier, constataram que a menor produção de leite foi obtida no tratamento com cana-de-açúcar. Os resultados obtidos também estão de acordo com os observados por BIONDI et al. (1978), que verificaram que até o teor de $50 \%$ de substituição da silagem de milho por cana-de-açúcar não houve efeito sobre a produção de leite.

Da mesma forma, COSTA et al. (2005) observaram queda tanto na produção de leite quanto na produção de leite corrigida para gordura (PLCG) quando $100 \%$ da silagem de milho foi substituída pela cana-de-açúcar ( $60 \%$ de volumoso na MS da ração). Os valores de produção encontrados foram 20,81 e $16,80 \mathrm{~kg} / \mathrm{dia}$ de leite, respectivamente. No caso da PLCG $(3,5 \%)$, os valores relatados foram $21,22 \mathrm{e}$ $17,76 \mathrm{~kg} / \mathrm{dia}$ de leite para os tratamentos silagem de milho e cana-de-açúcar, respectivamente. Por sua vez, VALVASORI et al. (1995), ao compararem o uso de silagem e da cana-de-açúcar, encontraram valores de produção de leite de $19,63 \mathrm{~kg} /$ dia para o tratamento silagem de milho; $18,94 \mathrm{~kg} /$ dia para o tratamento silagem de milho e cana-de-açúcar (50:50) e 18,07 kg/ dia para o tratamento cana-de-açúcar.

No presente experimento, as maiores produções de leite, observadas nos tratamentos com $100 \%, 75 \%$ e $50 \%$ de silagem de milho, ocorreram em razão dos maiores CMS desses tratamentos. Observa-se, na Tabela 2, que apenas a partir de $75 \%$ de inclusão de cana-de-açúcar no volumoso é que o CMS passou a ser severamente afetado, diminuindo, sem dúvida, a ingestão diária de energia.

Quanto aos componentes do leite, verificou-se na Tabela 2 que os tratamentos contendo $50 \%, 25 \%$ e $0 \%$ de silagem de milho apresentaram maior concentração $(P<0,05)$ de gordura quando comparados aos tratamentos contendo $100 \%$ e $75 \%$ de silagem de milho. Tal resultado pode ser atribuído à inclusão de caroço de algodão nas rações com teores crescentes de cana-de-açúcar. Outra possível explicação seria o efeito de diluição causado pela maior produção verificada nos tratamentos contendo $100 \%$ e $75 \%$ de silagem de milho. No entanto, a produção diária de gordura (kg/ dia) acompanhou o padrão verificado para produção de leite. $O$ teor de proteína do leite foi semelhante $(P>$ $0,05)$ entre os tratamentos. Entretanto, a produção diá- ria de proteína $(\mathrm{kg} / \mathrm{dia})$ foi menor para os tratamentos contendo $25 \%$ ou $0 \%$ de silagem de milho. Este fato pode ser explicado pelas alterações na fermentação ruminal, conforme constatado por PIRES et al. (2008). Esses autores avaliaram os efeitos da substituição de silagem de milho por cana-de-açúcar e caroço de algodão sobre os parâmetros ruminais e síntese microbiana de vacas em lactação, sendo observada redução no fluxo intestinal de matéria orgânica de origem bacteriana e de proteína bruta dietética nos animais alimentados com as rações contendo os maiores teores de inclusão de cana-de-açúcar (75\% e 100\%). De acordo com os autores, a redução no fluxo de proteína para o intestino pode limitar a disponibilidade de aminoácidos no trato digestivo posterior e reduzir a produção de leite. Adicionalmente, pode-se inferir que a produção de proteína no leite também pode ter sido prejudicada pela limitação de aminoácidos no intestino.

MAGALHÃES et al. (2004), ao compararem silagem de milho com cana-de-açúcar, não constataram alteração $(P>0,05)$ nos teores de gordura, proteína, extrato seco total e extrato seco desengordurado do leite quando vacas em lactação foram alimentadas com $0 \%, 20 \%, 40 \%$ e $60 \%$ de cana-de-açúcar na MS da ração. Os valores médios encontrados por esses autores foram 4,06\% de gordura; $3,56 \%$ de proteína; $13,38 \%$ de extrato seco total e $9,31 \%$ de extrato seco desengordurado. Contudo, a produção diária de todos os componentes foi menor $(P<0,01)$ de acordo com a inclusão de cana-de-açúcar, graças à queda na produção de leite. Da mesma forma, MENDONÇA et al. (2004) também não constataram alteração $(P$ $>0,05)$ nos teores de gordura, proteína, extrato seco total e extrato seco desengordurado do leite de vacas alimentadas com $60 \%$ de silagem de milho ou $60 \%$ de cana-de-açúcar na MS da ração. Os valores encontrados por esses autores foram $3,8 \%$ de gordura; $3,2 \%$ de proteína; $12,9 \%$ de extrato seco total e $9,1 \%$ de extrato seco desengordurado. De forma semelhante, COSTA et al. (2005) também não observaram diferenças nos constituintes do leite ao compararem uma ração com $60 \%$ de silagem de milho na MS e com outra contendo $60 \%$ de cana-de-açúcar na MS.

Dessa forma, as diferenças encontradas nesse experimento para os teores dos constituintes do leite são mais bem explicadas pelo efeito da inclusão do caroço de algodão. Esse alimento possui $50,3 \%$ de 
FDN e 19,3\% de extrato etéreo (NRC, 2001) e sua inclusão na dieta aumenta o aporte de gordura oriunda da ração para a glândula mamária, bem como o tempo de ruminação e de mastigação, em razão do seu línter ser ótima fonte de fibra efetiva (GRANT, 1997; MERTENS, 1997). Por fim, o maior valor de PLCG:CMS $(P<0,05)$ do tratamento contendo $25 \%$ de silagem de milho em comparação ao contendo $100 \%$ de silagem de milho pode ser atribuído à menor produção de calor de animais recebendo caroço de algodão, fato explicado pela elevada concentração de gordura nesse alimento (COPPOCK et al., 1987; ARIELI, 1998).

\section{CONCLUSÕES}

O consumo de matéria seca e a produção de leite mantiveram-se adequados até $50 \%$ de substituição de silagem de milho por cana-de-açúcar. A inclusão de caroço de algodão não foi capaz de manter o desempenho dos animais alimentados com as rações contendo substituições de $75 \%$ e $100 \%$ de silagem de milho por cana-de-açúcar. $\mathrm{O}$ teor de gordura do leite aumentou de acordo com a inclusão de cana-de-açúcar e o teor de proteína do leite não foi afetado. Em termos produtivos, é viável a substituição de $50 \%$ de silagem de milho por uma mistura de cana-de-açúcar mais caroço de algodão.

\section{REFERÊNCIAS}

ALLEN, M. S. Effects of diet on short-term regulation of feed intake by lactating dairy cows. Journal of Dairy Science, v. 83, n. 7, p. 1598-1624, 2000.

ARIELI, A. Whole cottonseed in dairy cattle feeding: a review. Animal Feed Science and Technology, v. 72, n. 1-2, p. 97$110,1998$.

AOAC - ASSOCIATION Of Official Analytical Chemists. Official methods of analysis. 15. ed. Arlington: AOAC, 1990. v. 1, 1117 p.

BIONDI, P.; CAIELLI, E. L.; FREITAS, E. A. N.; LUCCI, C. S.; ROCHA, G.L. Substituição parcial e total da silagem de milho por cana-de-açúcar como único volumoso para vacas em lactação. Boletim de Indústria Animal, v. 35, n. 1, p. 45-55, 1978.

COPPOCK, C. E.; LANHAM, J. K.; HORNER, J. L. A review of the nutritive value and utilization of whole cottonseed, cottonseed meal and associated by-products by dairy cattle. Animal Feed Science and Technology, v. 18, n. 2, p. 89-129, 1987.
COSTA, M. G.; CAMPOS, J. M. S.; VALADARES FILHO, S.C.; VALADARES, R. F. D.; MENDONÇA, S. S.; SOUZA, D. P.; TEIXEIRA, M. P. Desempenho produtivo de vacas leiteiras alimentadas com diferentes proporções de cana-de-açúcar e concentrado ou silagem de milho na dieta. Revista Brasileira de Zootecnia, v. 34, n. 6 (supl.), p. 2437-2445, 2005.

FOX, D.G.; TEDESCHI, L.O.; TYLUTKI, T.P.; RUSSELL, J.B.; VAN AMBURGH, M.E.; CHASE, L.E.; PELL, A.N.; OVERTON, T.R. The Cornell Net Carbohydrate and Protein System model for evaluating herd nutrition and nutrient excretion. Animal Feed Science and Technology, v. 112, n.1-4, p. 29-78.

GOERING, H.K.; VAN SOEST, P.J. Forage fiber analysis (apparatus, reagents, procedures and some applications). Washington: USDA, 1970. 20 p. (Agriculture Handbook, 379).

GRANT, R.J. Interactions among forages and nonforage fiber sources. Journal of Dairy Science, v. 80, n. 7, p. 1438-1446, 1997.

MAGALHÃES, A.L.R.; CAMPOS, J.M.S.; CABRAL, L.S.; MELLO, R.; FREITAS, J.A.; TORRES, R.A.; VALADARES FILHO, S.C.; ASSIS, A.J. Cana-de-açúcar em substituição à silagem de milho para vacas em lactação: parâmetros digestivos e ruminais. Revista Brasileira de Zootecnia, v. 35, n. 2, p. 591-599, 2006.

MAGALHÃES, A.L.R.; CAMPOS, J.M.S.; VALADARES FILHO, S.C.; TORRES, R.A.; MENDES NETO, J.; ASSIS. A.J. Cana-de-açúcar em substituição à silagem de milho em dietas para vacas em lactação: desempenho e viabilidade econômica. Revista Brasileira de Zootecnia, v. 33, n. 5, p. 1292-1302, 2004.

MENDONÇA, S.S.; CAMPOS, J.M.S.; VALADARES FILHO, S.C.; VALADARES, R.F.D.; SOARES, C.A.; LANA, R.P.; QUEIROZ, A.C.; ASSIS, A.J.; PEREIRA, M.L.A. Consumo, digestibilidade aparente, produção e composição do leite e variáveis ruminais em vacas leiteiras alimentadas com dietas à base de cana-de-açúcar. Revista Brasileira de Zootecnia, v. 33, n. 2, p. 481-492, 2004.

MERTENS, D.R. Creating a system for meeting the fiber requirements of dairy cows. Journal of Dairy Science, v. 80, n. 7, p. 1463-1481, 1997.

NATIONAL RESEARCH COUNCIL. Nutrient requirements of dairy cattle. $7^{\text {th. }}$ ed. Washington: National Academic Press, 2001. $381 \mathrm{p}$.

NAUFEL, F.; GOLDMAN, E.F.; GUARAGNA, R.N.; GAMBINI, L.B.; SCOTT, W.N.; KALIL, E.B. Estudo comparativo entre cana-de-açúcar e silagens de milho, sorgo e capim napier na suplementação de vacas leiteiras. Boletim de Indústria Animal, v. 26, n. 1, p. 9-22, 1969. 
NOGUEIRA FILHO, J.C.M.; LUCCI, C.S.; ROCHA, G.L.; MELOTTI, L. Substituição parcial da silagem de sorgo por cana-de-açúcar como volumosos para vacas em lactação. Boletim de Indústria Animal, v. 34, n. 1, p. 75-84, 1977.

PALMQUIST, D.L.; MATTOS, W.R.S. Metabolismo de lipídeos. In: BERCHIELLI, T.T.; PIRES, A.V.; OLIVEIRA, S.G. (Eds.). Nutrição de ruminantes. Jaboticabal: FUNEP, 2006. p. 287310.

PATE, F.M. Nutritive value of sugar cane at different stages of maturity. Tropical Animal Prodution, v. 2, p. 108, 1981.

PIRES, A.V.; SUSIN, I.; SIMAS, J.M.C.; SANTOS, F.A.P.; MENDES, C.Q.; OLIVEIRA JUNIOR, R.C.; FERNANDES, J.J.R.; ARAUJO, R.C. Substituição de silagem de milho por canade-açúcar e caroço de algodão nos parâmetros ruminais, síntese de proteína microbiana e utilização dos nutrientes em vacas lactantes.

Ciência Animal Brasileira, v. 9, n. 1, p. 50-58, 2008.

PRESTON, T.R. Nutritive value of sugar cane for ruminants. Tropical Animal Production, v. 3, n. 3, p. 211-217, 1978.
PRESTON, T.R. Nutritional limitations associated with the feeding of tropical forages. Journal of Animal Science, v. 54, n. 4, p. $877-884,1982$.

PRESTON, T.R.; CARCANO, C.; ALVAREZ, F.J.; GUTIÉRREZ, D.G. Rice polishings as a supplement in a sugar cane diet: Effect of level of rice polishings and of processing the sugar cane by derinding or chopping. Tropical Animal Production, v. 1, n. 3, p. 150-62, 1976.

SAS INSTITUTE. SAS/STAT Users Guide. 5. ed. Edition. Cary, NC.: SAS Institute Inc.,1991. 1028 p.

VALVASORI, E.; LUCCI, C.S.; ARCARO, J.R.P.; PIRES, F.L. A avaliação de cana-de-açúcar em substituição à silagem de milho para vacas leiteiras. Brazilian Journal of Veterinary Research and Animal Science, v. 32, n. 4, p. 224-228, 1995.

VAN SOEST, P.J.; ROBERTSON, J.B.; LEWIS, B.A. Methods for dietary fiber, neutral detergent fiber, and nonstarch polysaccharides in relation to animal nutrition. Journal of Dairy Science, v. 74, n. 10, p. 3583-3597, 1991.

Protocolado em: 22 out. 2008. Aceito em: 10 fev. 2010. 